\title{
A Primary Analysis on the Food Recall System: A Hard Mountain for China to Climb
}

\author{
Le Yang ${ }^{1}$, Tengfei $\operatorname{Tan}^{1}$, Zhongzhong $\mathrm{Wu}^{1}$, Sisi Zheng ${ }^{1}$, \& Jingmin Cheng ${ }^{1}$ \\ ${ }^{1}$ Shanxi Medical University, Taiyuan, Shanxi, China \\ Correspondence: Jingmin Cheng, School of Management, Shanxi Medical University, No.56 Xinjian South Road, \\ Taiyuan, Shanxi, China.
}

Received: May 12, 2015

Accepted: May 27, 2015

Available online: June 3, 2015

doi:10.11114/ijsss.v3i4.855

URL: http://dx.doi.org/10.11114/ijsss.v3i4.855

\begin{abstract}
Food safety concerns people's lives and property safety, the repeated food scandals of Chinese food safety brings a great shock at home and abroad. Chinese government has put forward many policies and schemes to solve the repeated food problems in China in recent years. There are several important measures in the process of dealing with the food safety problem. Among them, food recall is the most important and linking one that should be taken when the unsafe food has already flowed into the market. The establishment of Chinese food recall system has a great significance and shows a good start and a positive attitude of China in its long fight of food safety. However, in China, the food recall system is still in the bud and dose not get enough attention, many flaws and imperfection of Chinese food recall system has been revealed in its practical implementation. This paper attempts to find the flaws existing in Chinese food recall system and analyzes the complexity and diversity of Chinese present condition from the perspective of the theory of regulation. It's concluded that when the food safety supervisory authorities formulate the detailed plans or regulations of food recall system, they should explore a new path of food recall system and consider more the current condition and the specialty of the country rather than just put other countries' experience rigidly.
\end{abstract}

Keywords: food safety, food recall system, theory of regulation, problems

\section{Introduction}

Food safety is one of the attention focuses of governments all over the world, because it is closely linked to the life standard of people, the fame of a nation, and more importantly, the steadiness of a society (Wheelock, 1989; China Daily, 2010; Per \& Satoru, 2008). However, the present situation of Chinese food safety is serious, two growing food safety issues are illegal additives and contamination of the food supply by toxic industrial waste. China's connections to global markets are also having important effects on food supply and food safety within the country. Although the Chinese government has shown determination to reform laws, establish monitoring systems, and strengthen food safety regulation, the current situation of Chinese food safety governance remains weak and sever (Lam et al., 2013).

There are several important measures in the process of dealing with the food safety problem. Among them, food recall is the most important and linking one that should be taken when the unsafe food has already flowed into the market. As the Food Safety in China, the food recall system aims to recall the food that fails to meet food safety standards; the food that has already caused or has the possibility to cause food contamination, foodborne illness or the negative effects on people's health and death; the food containing the ingredients that have the potentially negative effects on the special populations gives the no, mistaken or not clear identification on the label or the introduction; and the other food failing to meet the relative food safety laws and regulations.

\section{Review of studies on food recall system in China}

Food recall system has been studied and discussed for many years by many famous scholars and experts (Hongu et al., 2015; Smith et al., 2014; da Silva et al., 2014). Till now, many experts and scholars in China have made the detailed researches on food recall system. Some papers study on Chinese food recall system based on the comparison of the food recall system in China and that in other countries, such as Tong analyses the defects of Chinese food recall system by comparing the food recall system in China and that in USA (Tong, 2011). She analyses Chinese food recall system from four aspects-legislative regulation, recall principal, recall procedure and punishment. Yuan suggests enhancing the food recall laws, implementing the initiative recall and order recall, establishing the effective recall administrative 
system, and improving food traceable system and recall information nets by comparing the food recall system of three typical countries - China, USA and Canada (Yuan, 2007). There are also some of papers and surveys analyzing exclusively Chinese food recall system or other countries'. For Chinese food recall, the current situation and the features of Chinese food recall system are discussed form food recall technology, surveillance administration and legislation (Liu, 2007). In his paper, the importance of local government and regulation was firstly mentioned. Considering the prepare work in the early stage of food recall, Zhao discusses about establishing the prewarning system of food security by monitoring base, and using these database to recall those unsafe food before they causing damage in a large scale, he talks about the government measures that aim to dealing with China's repeated food safety issues (Zhao, 2008). This paper reflects that the government not only makes effort to perfect the laws and regulations, what's more, to enhance the initiative and capacity of food companies in its dealing with the food safety problems.

Some papers focus on the food recall system in other countries. Wang makes a study on classification, key steps of Australian food recall system and how the food enterprises in Australia compose their food recall plans (Wang, 2006). Woolsey analyses American food recall system from the general mechanism, mainly from legislation, the judiciary and the executive (Woolsey, 2013). Most important, the paper tells us that although America adopt the separation of powers, its whole work mechanism is trinity.

Form these studies, it is obvious that the main stream of food recall research in China is discussing the current situation of food recall from the administrative tool-law, technology, surveillance organization, preventing and pre-warning system. Few of experts analyze the food recall system through the theory of regulation and notice the current condition of Chinese food industry which has its unique features and difficulties, the consumers who play an important role in the process of food recall, and the follow-up measures after the unsafe food has been recalled. Some experts who aim for making the macroscopic strategy usually do their studies from the general view, not from the specific part (Zhao, 2008). Some papers do the excellent analysis on other countries' food recall system, but it does not connect these clues with that in China (Woolsey, 2012; Wang, 2006).

\section{Relationship between the theory of regulation and food recall system}

\subsection{A short review of Chinese Food Recall System}

To promote the food recall campaign and avoid the unsafe food products flowing into food market and causing the great loss, Chinese government has started the food recall supervision campaign in the country positively, issued some food recall policies and encouraged people to report the unsafe food to the local government. In addition, some of the local government has also issued some documents or plans responding to the advocation of the central government. In 2007 the Regulations of The Food Recall System has been established. It clearly identifies the unsafe food and the recall, lists the procedure and punishment of food recall and the related risk evaluation standards in detail, defines the supervisory department of the unsafe food recall and illustrates how to tackling the unsafe food after the recall.

The food recall system has been defined for the first time in the law-article 53 of the Food Safety Law of The People's Republic of China-implemented on 1st June, 2009. The draft regulation requires government agencies to integrate official overseas visits, public vehicles and maintenance and official receptions into their budget control, and devise spending plans for these items.

According to The Food Safety Law of People's Republic of China (The State Council, 2009), generally, the food recall system comprises two aspects: active recall and instructed recall. Active recall is that The system stipulates that it is the responsibility of food producing and processing enterprises to recall their products if necessary, requires that food producers should instantly put a halt to the production and selling of their products if they suspect any safety risk in their food products, and take the initiative to recall such food products. Instructed recall is that when producers who purposely conceal food hazards or do not perform their recall obligations, or whose faulty production has extended such hazards or made them recur, will be instructed to recall their products.

There is such a phenomenon existing in Chinese food industry that the industry itself has developed a lot, but the relative laws and regulations have not gotten renewed at the same speed, on the contrary, far behind other countries, due to the neglect of its importance. The high increase rate combined with the low regulatory level make Chinese food industry developed in malformation and lead to the difficulties in the latter food recall.

In China, food safety accidents have been frequently exposed in recent years, especially in 2011. The food safety problem once again becomes a focus of public concern, such as Shuanghui clenbuterol event, "dyeing steamed bread" event appeared in Hualian and many supermarkets in Shanghai, toxic leek event in Nanyang Henan, milk nitrite poisoning event in Pingliang Gansu, small whitebait soaked by formalin events in Qingdao Shandong, excessive "swollen agent" used in watermelon event, etc (Chen, 2003). Food safety problems seriously threaten people's health, and damage the image of enterprises and even the nation. 
Nonetheless, the implementation of this regulation seems not as effective as the government expected. Numerous unsafe food recalls are delayed and cannot successfully avoid the harm in time. Many people and press media all over the world, throw their sharply and extreme critics to Chinese governments, saying that the government is just the window-dressing, that the governors get the high salary without doing anything meaningful for the people, or that the governors are corrupted, they collude with those food producers and cover up the food producers' illegal actions ( $\mathrm{Lu}$, 2014; Li, 2013). Chinese economy and politics have been affected seriously. The slow recall makes China in the dilemma. The food industry is faltered and disordered and the credibility of the government is lowed at home, and the international reputation and image of China are damaged and its import and export trade is blocked on a global scale.

\subsection{Application of the theory of regulation}

With the theory of regulation, we realized that the guarantee of food safety in China should be taken by the government, but also the food enterprise and the consumer. Regulation is instituted primarily for the protection and benefit of the public at large or some large subclass of the public (George, 1971). In the process of food safety regulation, there are four parts--the regulation subject (the government and other administrative organizations), object (the food safety problems and the food enterprise), measures (laws, economic punishment, media supervision, etc.), and objective (food safety)--play importance role in the process of guarantee of food safety and the relationship between the four parts is systematic and interoperable (Tollison, 1991).

As for the establishment and implementation of food recall system in China, the cooperation between the government, the food enterprise, the consumer and the press media is not well. For example, when the Shuanghui clenbuterol event was disclosed, the government could not recall the unsafe food in time, the food enterprise did not recalled their product actively and not explained and apologized to the consumer as well, what' s more, the events and truth was exaggerated by the press, finally, all of these caused the panic among the consumer and the disorder of the food market.

\section{Stumbling Blocks of Chinese Food Recall}

\subsection{Attitudes Affecting People's Behaviors}

China has long history of feudalism and special economic pattern, the small peasant economy formed the closed and conservative thoughts. And the thoughts still influence the consuming behaviors and attitudes of modern people. For the food safety problems, some people will say indifferently "someone else, not me, screwed up.", so they do not need to draw their attention to the food safety information. As what we often see in our daily life-older people have the best food handling skills, but are the least knowledgeable and least concerned about risks. Younger people have the most knowledge and concern about risks, but continue to eat risky foods and display risky behavior. More educated consumers are more likely to eat risky foods and show no better food handling procedures than less educated consumers.

Actually, Chinese citizens know a little about food recall and its significance, especially for those who live in the poverty-stricken districts (Huang et al., 2014), because they are so feared after being bombarded with all kinds of deadly food additives revealed on the newspapers and televisions. But Chen explains that "In fact, the food additives that conform to the country's requirements are necessary and safe" (Chen, 2003). Some people keen to pursuing the foreign brands and believe the import foods are better than the domestic foods, because they lose confidence to the domestic foods under the exaggerated release of the domestic unsafe foods, some people even do not know how to choose food product, the really safe one ( $\mathrm{Li}, 2011$; Zhao \& Zhou, 2012).

Overcoming these attitudes is a major hurdle leading people to change their behaviors, which blocks the discovery and recall of the unsafe food, and makes people easier to become victims of unsafe food. So when the government makes the plans of the food recall system, it should regard consumers as a force contributing to the implementation of the unsafe food recall. Strengthen the education of the food safety in the primary consumers, improve their law and health consciousness to the unsafe food, establish an interaction mechanism between consumers and the government, as well as between the consumers and the food products companies.

\subsection{Features of Chinese food industry}

The features of Chinese food industry decide the complexity and difficulty of the implementation of the food recall system. Theoretically, food products companies should play the main role in the food recall, but actually this theory cannot work in China, because most of Chinese food products companies are small, scrawled, and not really confined by the law.

According to White Paper on Food Quality and Safety (The State Council 2007), the official data shows that in 2007 China had 448,000 enterprises engaged in foodstuff production and processing. Among them (Figure 1), 26,000 enterprises of designated scale 1 occupy 72 percent of the market; 69,000 were enterprises not up to the designated scale and those with more than ten employees; and 353,000 were small businesses or workshops with fewer than ten 
employees.

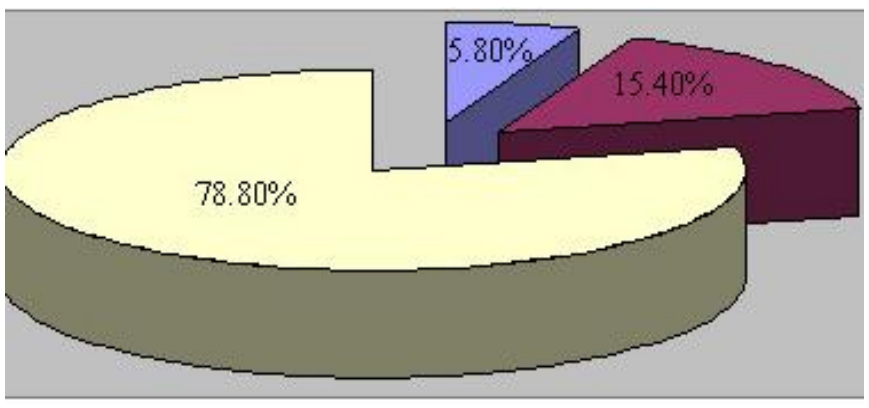

Enterprises of designed scale

Enterprises not up to the designed scale and those with more than ten employees

Small businesses and workshops with fewer than ten employees

Figure 1. Chinese food enterprises in three types

Source:http://www.chinadaily.com.cn/china/2007-08/17/content_6032557.htm

In general, the main influencing factors for the food companies do not recall the unsafe food are as follows:

1) Low quality of some of the food producers, distributors and retailers

Due to the loose supervision, high-profit and low technological requirements of food industry, many people flood into it. Most of them have not gotten high education, and they do not know the exquisite recipes of the food products. Driven by the high profits, they try to lower the cost extremely by using fake and chemical raw materials and producing and processing the food products in humble or even filthy environment, and then they sell the products to all parts of the country (Yan \& Zhang, 2012; Mi \& Hua, 2014). Disclosed by the press media or the government, the unsafe food producers and processors are demanded to recall their products, but these unqualified food still have a certain demand. The cunning and black-heart food producers and processors superficially recall the unsafe food and claim they will stop making the unsafe food products trade in the market, in the other hand, they are engaged in building a new factory, which is more remote and secret.

2) Unclear existence and location of small companies

Various small food processing factories and workshops scrawl in a private and mobile form, and run without authorization, so there has not a relatively comprehensive information system among the food companies. Even though the government works so hard to accelerate the food recall and strengthen the management of the involved companies, many illegal small companies built in village, rural-urban area or even their home are out of the control of government (Wang, 2007; Chen \& Liu, 2012). These small companies are difficult to be found by local supervisory departments, the unqualified food is always produced and sold. The extermination of the concealed small companies is a big problem for China that will affect seriously the food recall.

3) High cost of small companies in recalling the unsafe food products

As a part of the responsibility insurance, the food recall responsibility insurance contributes to spreading the responsibility of food companies, making the role of food recall get full play. In China, no protective insurance system has been established for food companies, and the country take a relative high tax for them, with the result that the profits of the small companies is little. For the legal small companies, the unqualified food recall means a large expenditure. It is inevitable for them to be bankrupted after they complete the recall. Under this circumstance, it is difficult to demand these companies recall their food products actively.

4) Delay in knowing the information of the unsafe food.

Some food companies get the information of the unsafe food and the new laws and regulations slowly and not comprehensively, for their remote location or the restraints of technology. Most of food risk analysis devices are old and retarded. As a result, when they found the unsafe factors in their food products, the harm have happened to consumers.

\subsection{Undefined Follow-Up Measures of Food Recall}

The food recall system has only been established for a short time, many of the detailed rules are not very perfected. The Food Recall Regulations, which is comparatively completed and comprehensive in China, has defined many detailed rules in the process of food recall, including the recall form, government supervision and evaluation, and follow-up check and tackling. But it has not clearly mentioned the trigger of the unsafe condition of the food products. It is uncertain whether the human factors cause it happened, like using the poisonous food additives, selling the expired food; or the natural factor, for example, the bad bacteria grows as a result of the long-time exposure of the foods to the wet and hot environment. Nor has it discussed about further studying of the toxic factor in its feature and transformation. 
What's more, we do not know what those toxic substances we have discovered in the unsafe food are. The government and the food companies have not given a formal and full explanation or education for consumers about; how terrible the result will become if people eat them unconsciously. Without well understanding of the recalled unsafe food, consumers may show a possible fear and rejection to the similar products of other brands. The purpose of the unsafe food recall is to protect consumers from the potential hazards, and the best way is letting the consumer have an idea about it. The similar education should also be provided among food producers. Not realizing the gigantic hazards of the unsafe food, after the recalls of the unsafe food, many food producers just change the package and market it again, which finally will cause the consumption sags and bring the food industry to a grinding halt.

\section{What's the future of food recall system in China?}

China, which is different from the developed countries, has its special condition. The superiority is that as a socialism country, the government can focus all kinds of resource, to a high extent, on solving the problem emerging in the process of its economic construction, while the disadvantage that its large population is difficult to manage entirely and that stereotyped attitude and work allocation formed in a long-term feudalism history is hard to overcome.

Even though, over the years, the continuous growth of the national economic development as well as the people's living standard and their consumption demands pose higher and higher demands in food quantity, quality and variety, Chinese social condition has not gotten a dramatic and historical transformation and the historical, economic, and political factors still exist and make their contributions. Then the great contradiction between the rapid development of food industry and the disordered food market appears makes Chinese food industry challenged constantly and makes the food recall in China more difficult. The government has not yet gained the expected results after it sparing no effort to make some progress in the unsafe food recall. Under China's complicated and varied situation, the experts and supervisory departments need a long period to research the root problems and explore the long-term efficient solution.

In addition, adopting some of the successful experience of other countries is also important. As an old saying goes, we should look at the world by standing on the giant's shoulder. But we must also remember that what is good for us is what really fit us. Therefore we should learn those regulations, methods, and systems with a clear consciousness of China's situation.

The food recall is a work that needs to be accomplished with a long-time and constant efforts. On the basis of theory of regulation, combining with the theory of risk society, principles of economics and legal theory (Ching \& Yun, 2010), Chinese citizens should participate in the supervision of food safety rather than just complain about the failure of Chinese government in implementing the food recall system, the consumers should strengthen their confidence to the government and Chinese food industry, the government should perfect its supervision structure, and the food producers should set up the right profit view and improve their producing technology. The road to victory will be explored with the combined efforts of the government, food producers and consumers.

\section{References}

Chen, J. S. (2003). Food safety - China's major public health problem. China J Epidemiol., 24(8), 649-650.

Chen, Y., \& Liu, H. (2012). The Responsibilities Division of Governmental Supervision and Administration on Small Food Production or Processing Workshops and Food Vendors. Journal of Wenshan Teachers College, 25(3), $117-120$.

China Daily (2010). China vows new food safety campaign (Xinhua). http://www.chinadaily.com.cn/2010-02/10/content_9453301.htm

Ching, L., \& Yun, Z. (2010). Reformation of voluntary food recall system from the angle of the theory of risk society. Agriculture and Agricultural Science Procedia, 1, 296-300.

da Silva, M. M., Sala P. C., Torrinhas R. S., \& Waitzberg D. L. (2014). Efficiency of the 24-hour food recall instrument for assessing nutrient intake before and after Roux-en-Y gastric bypass. Nutr Hosp., 30(6), 1240-1247. http://dx.doi.org/10.3305/nh.2014.30.6.7828.

George, J. S. (1971). The theory of economic regulation. The Bell Journal Economics and Management Science, 1(2), 3-21. http://www.sjsu.edu/faculty/watkins/stigler.htm

Hongu, N., Pope, B. T., Bilgiç, P., Orr, B. J., Suzuki, A., Kim, A. S., Merchant, N. C., \& Roe, D. J. (2015). Usability of a smartphone food picture app for assisting 24-hour dietary recall: a pilot study. Nutr Res Pract., 9(2), 207-212. http://dx.doi.org/10.4162/nrp.2015.9.2.207.

Huang, D., Sun, Z., Hu, J., Shen, M., Peng, Z., \& Zeng, N. (2014). Effect of nutrition and food safety education among middle school students in a poverty-stricken county in west China. Zhong Nan Da Хие Хие Bao Yi Хие Ban., 39(3), 313-319. http://dx.doi.org/10.11817/j.issn.1672-7347.2014.03.015. 
Lam, H. M., Remais, J., Fung, M. C., \& Xu, L. (2013). Food supply and food safety issues in China. The Lancet, 381(9882), 2044-2053.

Li, W. H. (2013). An In-Depth Analysis of the Food Safety Issues. Journal of Shanghai Normal University (Philosophy \& Social Sciences), 2, 55-65.

Li, X. (2011). A Signaling Model for the Quality of Credence Goods: Taking the Food Safety Problem as Example. WORLD ECONOMIC PAPERS, 1, 87-108.

Liu, W. (2007). The current situation and characteristics of food recall system in China. Food Science and Technology, $12,1-4$.

Lu, Z. K. (2014). Research on the Government Regulation Failure of Food Safety Problems---Example of Rent-seeking. Food Research and Development, 18, 170-172.

Mi, L., \& Hua, X. (2014). Study on Social Responsibility of Food Corporation Based on the Food Safety Perspective. Food Research and Development, 18, 111-114.

Per, P. A., \& Satoru, S. (2008). Do poverty and poor health and nutrition increase the risk of armed conflict onset?, Food Pol., 33, 513-520.

Smith, L. P., Hua, J., Seto, E., Du, S., Zang, J., Zou, S., Popkin, B. M., \& Mendez, M. A. (2014). Development and validity of a 3-day smartphone assisted 24-hour recall to assess beverage consumption in a Chinese population: a randomized cross-over study. Asia Pac J Clin Nutr., 23(4), 678-690. http://dx.doi.org/10.6133/apjcn.

The State Council of the People's Republic of China (2007). White Paper on Food Quality and Safety (China Daily). http://www.chinadaily.com.cn/china/2007-08/17/content_6032557.htm

The State Council of the People's Republic of China (2009). The Food Safety Law of People's Republic of China. http://english.mofcom.gov.cn/aarticle/policyrelease/announcement/201003/20100306819063.html

Tollison, R. D. (1991). Regulation and interest groups in regulation-economics and history. Edited by Jack High, Michigan Press.

Tong, X. J. (2011). The discussion about Chinese food recall system- perspective of combination with American food recall system. Journal of Longyan University, 3, 121-124.

Wang, R. C. (2006). The food recall system and its characteristics of Australia. Chinese Journal of Food Hygiene, 1, 61-63.

Wang, S. W. (2007). Thought about Supervision to Food Workshops in Our Country. WORLD STANDARDIZATION \& QUALITY MANAGEMENT, 5, 55-58.

Wheelock, V. (1989). Food safety in perspective. British Food Journal, 93, 31-36.

Woolsey, M. (2013). The food safety in America. The Global Food Safety Forum: the food safety management of whole food chain. Beijing.

Yan, Y. J., \& Zhang, Y. N. (2012). Based on food safety construction and research on ethics of food companies. Food \& Machinery, 28(6), 236-238.

Yuan, J. Q. (2007). The current status and analysis on the food recall system of some of the developed countries. Chinese Journal of Food Hygiene, 6, 529-533.

Zhao, X. G., \& Zhou, Y. (2012). Research of the reconstructing consumer trust to food safety: From the perspective of regulating food operator. Science and Technology of Food Industry, 33(4), 458-461.

Zhao, Y. H. (2008). The key point and the pre-warning system of food safety in China. Practical Preventive Medicine, 1 , 30-33.

\section{(cc) $\mathrm{Br}$}

This work is licensed under a Creative Commons Attribution 3.0 License. 